\title{
3D Centrifuge Modeling of the Effect of Twin Tunneling to an Existing Pile Group
}

\author{
Mukhtiar Ali Soomro \\ Dpt. of Civil Engineering \\ Quaid-e-Awam University \\ of Engineering, \\ Science \& Technolgy \\ Nawabshah, Pakistan \\ eng.soomro@gmail.com
}

\author{
Manthar Ali Keerio \\ Dpt. of Civil Engineering \\ Quaid-e-Awam University \\ of Engineering, \\ Science \& Technolgy \\ Larkana, Pakistan \\ Mantharali99@quest.edu.pk
}

\author{
Mohsin Ali Soomro \\ Dpt. of Civil Engineering \\ Quaid-e-Awam University \\ of Engineering, \\ Science \& Technolgy \\ Nawabshah, Pakistan \\ drmohsin@quest.edu.pk
}

\author{
Daddan Khan Bangwar \\ Dpt. of Civil Engineering \\ Quaid-e-Awam University \\ of Engineering, \\ Science \& Technolgy \\ Nawabshah, Pakistan \\ daddan@quest.edu.pk
}

\begin{abstract}
In densely built urban areas, it is inevitable that tunnels will be constructed near existing pile groups. The bearing capacity of a pile group depends on shear stress along the soil-pile interface and normal stress underneath the pile toe while the two would be adversely affected by the unloading process of tunneling. Although extensive studies have been conducted to investigate the effects of tunnel construction on existing single piles, the influence of twin tunnel advancement on an existing pile group is merely reported in the literature. In this study, a series of three-dimensional centrifuge tests were carried out to investigate the response of an existing pile group under working load subjected to twin tunneling at various locations in dry Toyoura sand. In each twin tunneling test, the first tunnel is constructed near the mid-depth of the pile shaft, while the second tunnel is subsequently constructed either next to, below or right underneath the pile toe (Tests G_ST, G_SB and G_SU, respectively). Among the three tests, the 2nd tunnel excavated near the pile toe (Test G_ST) results in the smallest settlement but the largest transverse tilting $(0.2 \%)$ of pile group. Significant bending moment was induced at the pile head (1.4 times of its bending moment capacity) due to the $2 n d$ tunnel $T$. On the contrary, tunneling right underneath the toe of pile (i.e., Test G_SU) results in the smallest tilting but largest settlement of the pile group (4.6\% of pile diameter) and incremental mobilisation of shaft resistance $(13 \%)$. Due to stress release by the twin tunneling, the axial force taken by the front piles close to tunnels was reduced and partially transferred to the rear piles. This load transfer can increase the axial force in rear piles by $24 \%$.
\end{abstract}

Keywords-twin tunneling; pile group; three-dimensional; soilstructure interaction; centrifuge modeling

\section{INTRODUCTION}

Due to land shortage, high-rise buildings are preferred to meet the development and economical growth in major cities. The construction of high rise buildings often requires deep foundations such as pile group when the underlying soil and rock strata do not have sufficient bearing capacity. In densely built urban cities, tunnels are likely to be constructed adjacent to existing deep foundations. One recent example is MRT North East line C704 project in Singapore, in which twin tunnels were carried out near the shaft of an existing pile group
[1]. It is well recognized that the capacity of a pile group depends on mobilized stresses in the ground while tunneling is essentially a stress release process. Therefore, it is vital to investigate the adverse effects of tunneling on existing pile foundations. There have been a number of studies addressing this problem. Among previous studies, numerical analyses, analytical solutions and centrifuge modeling are most frequently adopted [2-16]. Generally speaking, tunneling adjacent to existing pile foundations, results in substantial changes in the axial load of piles and in pile settlement. Both are found to heavily depend on tunnel location in relation to the pile. However, these studies focused on pile response to single tunneling. However, twin tunneling has been increasingly constructed while developing underground metro lines [17]. Excavation of twin tunnels adjacent to existing pile foundations would result in more complicated load transfer mechanisms within a single pile or between piles in a group. Accordingly, settlement or tilting of pile foundations would be more concerned.

As far as field monitoring is concerned, very few researchers have investigated the effects of twin tunneling on piles. In [1], authors reported a case history of twin shield tunneling adjacent to an existing pile group in Singapore. However, instrumentation only includes strain gauges along a limited portion of piles near tunnels. Settlement and tilting of the pile group were not reported. Regarding model tests, authors in [18] carried out two centrifuge tests to investigate influence of construction sequences of twin tunneling on an existing single pile in medium dense dry sand. The two construction sequences considered are: (i) tunneling near the middle of the pile shaft followed by tunneling near the pile toe (Test ST); (ii) tunneling near the pile toe followed by tunneling near the middle of the pile shaft (Test TS). It is concluded that the measured pile settlement caused by tunneling sequence ST is $33 \%$ larger for than by tunneling sequence TS. A larger reduction in the end bearing resistance and shaft resistance at the lower part of the pile is resulted from tunneling near the pile toe in Test ST than in Test TS. On other hand, construction sequences have limited effect on ground surface settlement and bending moment of pile. Location of tunnels relative to the pile, which were shown to significantly affect pile response by 
previous study, was not considered in this study. To investigate responses of pile group subjected to twin tunneling at various locations, a series of centrifuge were carried out in this study. The test series consists of one pile load test in "greenfield" and three other tests with tunnels constructed at various locations relative to an existing pile group. Measurements in the centrifuge tests include settlement and tilting of the pile group, axial load and bending moment of each pile at various tunneling stage.

\section{EXPERIMENTAL PROGRAM AND SETUP}

It is well recognized that soil behavior is stress-dependent. By using a geotechnical centrifuge, a proper stress field can be recreated in a soil model by applying centrifugal acceleration $\mathrm{N}$ times greater than Earth's gravitational acceleration (g).

TABLE I. SUMMARIZES SCALE FACTORS RELEVANT TO THIS STUDY.

\begin{tabular}{|c|c|}
\hline Physical quantity & $\begin{array}{c}\text { Scaling factor } \\
\text { (model } / \text { prototype) }\end{array}$ \\
\hline Gravitational acceleration & $\mathrm{n}$ \\
\hline Length & $1 / \mathrm{n}$ \\
\hline Area & $1 / \mathrm{n}^{2}$ \\
\hline Volume & $1 / \mathrm{n}^{3}$ \\
\hline Settlement & $\mathrm{n}$ \\
\hline Stress & 1 \\
\hline Strain & 1 \\
\hline Force & $1 / \mathrm{n}^{2}$ \\
\hline Density & 1 \\
\hline Mass & $1 / \mathrm{n}^{3}$ \\
\hline Flexural rigidity & $1 / \mathrm{n}^{4}$ \\
\hline Bending moment & $1 / \mathrm{n}^{3}$ \\
\hline
\end{tabular}

In this study, four centrifuge model tests were carried out at the Geotechnical Centrifuge Facility of the Hong Kong University of Science and Technology [19, 20]. The 400 g-ton centrifuge has an arm radius of $4.2 \mathrm{~m}$ and is equipped with a two-dimensional hydraulic shaking table and a four-axis robotic manipulator. All of centrifuge tests reported herein were carried out at a centrifugal acceleration of $40 \mathrm{~g}$. Figure 1a shows elevation view of Test G ST, which is intended to investigate responses of a pile group due to tunneling near the mid-depth of pile shaft and subsequently near the pile toe. The shallow tunnel was simulated prior to the deep one, since this construction sequence was shown to affect pile settlement more severely, than the reversed sequence [18]. The horizontal distance from the centerline of the tunnel to the nearest pile is $0.75 \mathrm{D}$. Diameter and length of each pile are $20 \mathrm{~mm}(0.88 \mathrm{~m}$ in prototype) and $600 \mathrm{~mm}$ (24.0 $\mathrm{m}$ in prototype), respectively. The pile cap was elevated by $110 \mathrm{~mm}$ (above the ground surface) and hence the embedded depth of each pile is $490 \mathrm{~mm}$ (19.6 $\mathrm{m}$ in prototype). Diameter of each tunnel $(D)$ is $152 \mathrm{~mm}$ (6.08 $\mathrm{m}$ in prototype). Cover-to-diameter ratios $(C / D)$ of the tunnels located near the pile shaft and pile toe are 1.5 and 2.7, respectively. Figures $1 \mathrm{~b}$ and $1 \mathrm{c}$ show elevation view of Tests G_SB and G_SU, respectively. In these two tests, the first tunneling is carried out at the same location as that in test G_ST $(C / D=1.5)$, while the second tunnel in both Tests G_SB and G_SU is constructed below and right underneath the toe of the pile group $(C / D$ ratios in both tests are equal to 3.7$)$, respectively.

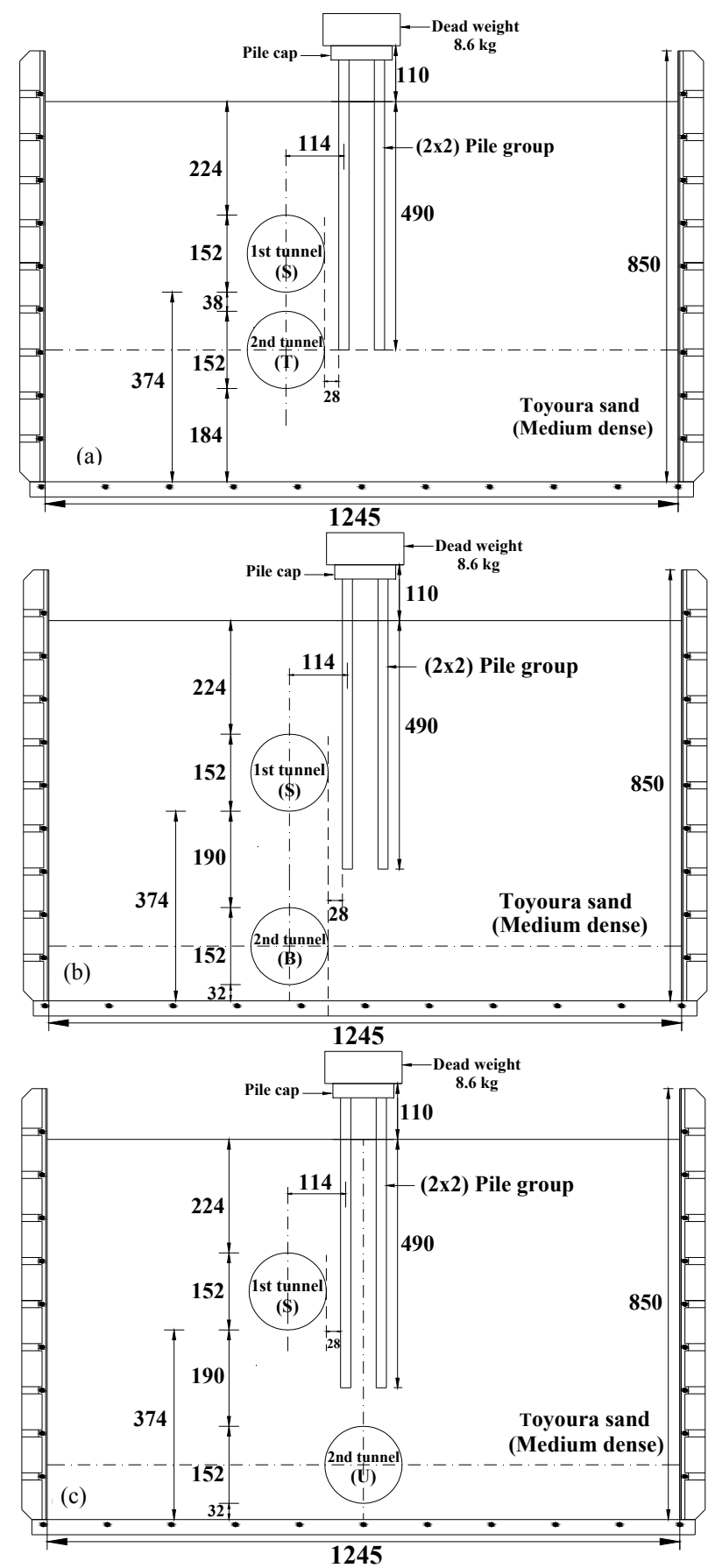

Fig. 1. Elevation view of centrifuge tests: (a) G_ST; (b) G_SB and (c) G_SU. All dimensions are in $\mathrm{mm}$ in model scale

Figure 2a illustrates plan view of a typical test (i.e., Test G_ST). It can be seen that length of each model tunnel (along 
its longitudinal direction) is $380 \mathrm{~mm}$, which is equivalent to 2.5D. Each tunnel consists of five construction stages, with the tunnel face advancing by a distance of $0.5 D$ in each stage. In addition to the three tests described above, in-flight pile load test (Test G_L) is carried out to obtain the load settlement curve of the pile group in "greenfield" (i.e., with absence of tunnels). Table II summarizes centrifuge test program in this study.
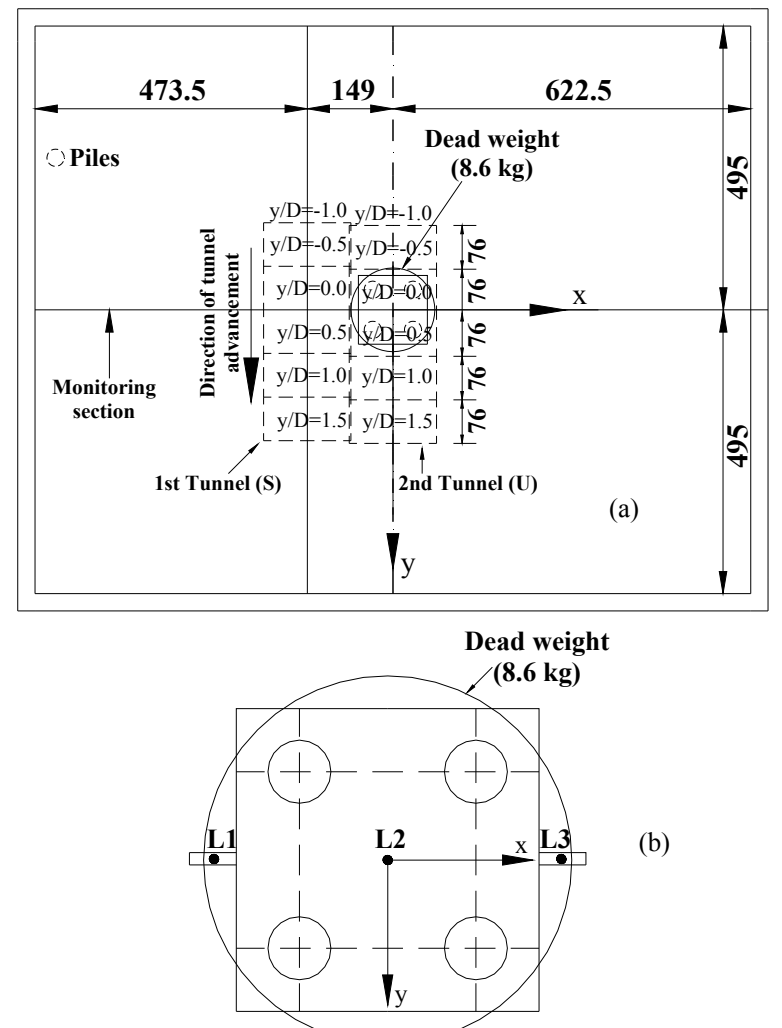

Fig. 2. (a) Plan view of a typical centrifuge test (Test G_SU) (all dimensions are in $\mathrm{mm}$ in model scale); (b) instrumentation at the pile cap

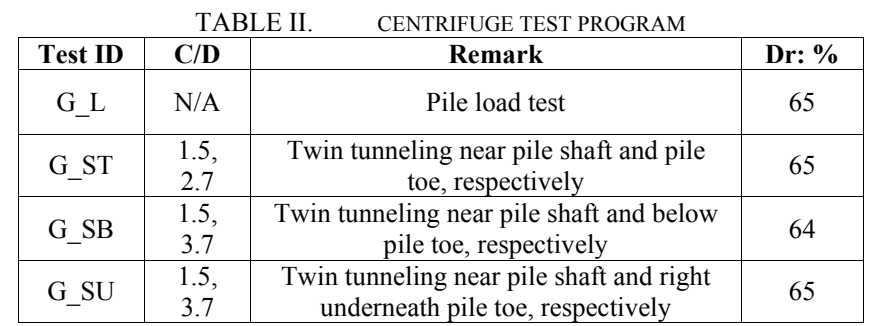

\section{A. In-Flight Simulation ofTtunnel Excavation}

In each twin tunneling test (except the pile load test), each model tunnel consists of five independent cylindrical rubber bags (see Figure 2a). Each rubber bag was filled with de-aired water. Three-dimensional tunnel excavation was simulated inflight by draining away a controlled amount of water from each rubber bag one by one. The amount of water drained away from each rubber bag was equivalent to a volume loss of $1.0 \%$.
Draining water from the rubber bag at $40 \mathrm{~g}$ caused deformation mostly at the top of the rubber bag but small at the bottom because of the weight of the bag/water. This is similar to the characteristics of ground deformation caused by a shield tunnel, near which ground mainly deforms at the tunnel crown and sides $[21,22]$ while very small ground displacement takes place at the tunnel invert $[23,24]$.

\section{B. Model Pile Group and Instrumentation}

A $2 \times 2$ model pile group was used to replicate $0.88 \mathrm{~m}$ diameter of concrete piles at prototype scale in this study as shown in Figure 3. The four piles were connected to a relatively rigid pile cap, which corresponds to a $1 \mathrm{~m}$ thick reinforced concrete cap in prototype with a flexural rigidity of $15 \mathrm{GNm}^{2}$. Each model pile was made of an aluminum tube with a Young's Modulus of $70 \mathrm{GPa}$. The aluminum tube was $600 \mathrm{~mm}$ long and it had outer and inner diameters of 19 and 15 $\mathrm{mm}$ (i.e., wall thickness $=2 \mathrm{~mm}$ ), respectively. Each pile was instrumented with semiconductor strain gauges (SGs) bonded on external surface of the piles at ten levels at spacing of 60 $\mathrm{mm}$ ( $2.4 \mathrm{~m}$ in prototype scale) to measure axial load and bending due to tunneling. Full Wheatstone bridge strain gauges were arranged for temperature compensation for axial and bending. These SGs have a guage factor (GF) 150 which is higher than conventional foil gauges $(\mathrm{GF}=2)$. It implies that these strain gauges are able to measure strain as low as $\pm 1.5 \mu$ strains. Each pile was calibrated for the axial and bending measurement prior to each test. For axial calibration, each pile was applied force gradually on the top of pile using actuator. The corresponding outputs were then related to axial forces. For bending calibration, each pile was placed on two knife edges supports at each end of pile, making pile as simply supported beam. Then different weights were hanged not only at centre but also at distance of one-third and two-third from left support. Strain gauge outputs were then related to calculated bending moments.

The SGs were protected by a $1.5 \mathrm{~mm}$ thick epoxy coating uniformly applied to the shaft of each pile. The epoxy was not coated with sand. To measure the interface property between Toyoura sand and epoxy-coated pile shaft, two direct shear tests were carried out. The measured average friction angle of the Toyoura sand-expoxy interface was $18^{\circ}$. In addition, the surface roughness was measured using an optical profiler. The measured absolute interface roughness $R_{\max }$ is approximately $15 \mu \mathrm{m}$. The normalised roughness $R_{n}$, which is defined in [25] as a ratio of $R_{\max }$ to the mean particle size of sand $\left(D_{50}\right)$ is 0.09 . Author in [26] classified interfaces with $R_{n}$ smaller than 0.02 as smooth interfaces and interfaces with $R_{n}$ larger than 0.10 as completely rough interfaces. Based on this criterion, the pilesoil interface in this study may be described as relatively rough. By taking stiffness of the epoxy coating (Young's modulus $=2$ $\mathrm{GPa})$ into account, axial rigidity $\left(\mathrm{E}_{\mathrm{m}} \mathrm{A}_{\mathrm{m}}\right)$ and bending rigidity $\left(\mathrm{E}_{\mathrm{m}} \mathrm{I}_{\mathrm{m}}\right)$ of each model pile are $7670 \mathrm{kN}$ and $284 \mathrm{Nm}^{2}$, respectively. According to scaling factors summarized in Table $\mathrm{I}$, the corresponding $\mathrm{E}_{\mathrm{m}} \mathrm{A}_{\mathrm{m}}$ and $\mathrm{E}_{\mathrm{m}} \mathrm{I}_{\mathrm{m}}$ of each pile in prototype scale are $12,272 \mathrm{MN}$ and $727 \mathrm{MNm}^{2}$ in prototype, respectively. Linear variable differential transformers (LVDTs) were installed at various places of the pile cap (see Figure $2 b$ ) to measure settlement of the pile group ("L2"), transverse tilting 
of the pile group (deduced from measurement of "L1" and "L3").

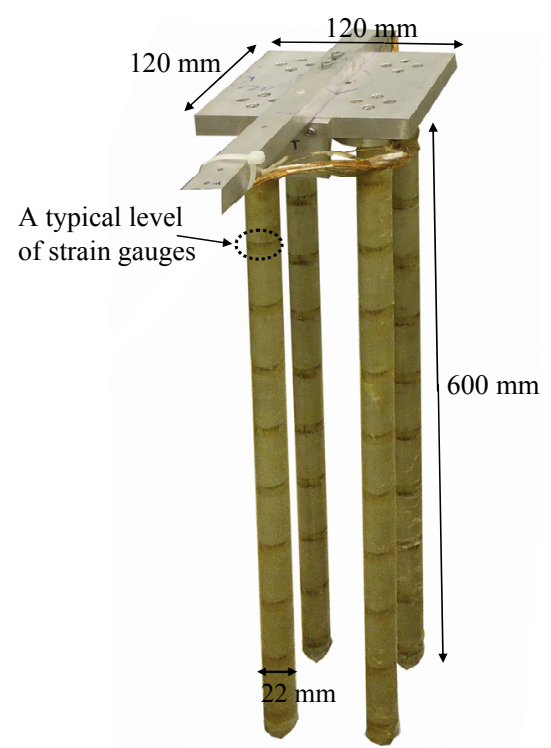

Fig. 3. Model pile group and instrumentation (all dimensions are in $\mathrm{mm}$ in model scale)

\section{Pile Loading System}

In the pile load test (Test G_L), a vertical load was applied to the pile cap incrementally using a hydraulic jack. Each load increment is controlled by a load cell attached to the piston of the hydraulic jack. While settlement of the pile group is measured by a LVDT located at the centre of the pile cap. Based on the pile load test, working load of the pile group can be determined according to a displacement controlled criterion (discussed later). The obtained working load is then applied to the three tests with tunneling simulated (Tests G ST, G SB, G_SU), by mounting a dead weight on top of the pile cap before centrifuge testing (at $1 \mathrm{~g}$ ).

\section{Testing Material and Model Preparation}

According to author of [27], Toyoura sand consists of subangular particles and has a mean diameter $\left(D_{50}\right)$ of $0.17 \mathrm{~mm}$ and a uniformity coefficient $\left(\mathrm{U}_{\mathrm{c}}\right)$ of 1.7 . The maximum and minimum void ratios of the sand are 0.977 and 0.597 , respectively. Regarding grain size effects, authors in [28] suggested that the grain size of soil only becomes significant when it exceeds $1 / 30$ th of an important model dimension such as pile diameter. In this study, the grain size of Toyoura sand $(0.17 \mathrm{~mm})$ is only $1 / 118$ th of the pile diameter $(20 \mathrm{~mm})$, suggesting that the scale effects on load carried by the pile toe are likely to be negligible. In each test, the model sandy ground was prepared by pluvial deposition method (i.e., raining dry Toyoura sand into the model box) at $1 \mathrm{~g}$. During the sand raining process, a constant falling height of sand (i.e., $500 \mathrm{~mm}$ ) was maintained to result in medium-dense sand (with relative density of about $65 \%$, based on previous calibrations). When the sand bed reached the elevation where the invert of the tunnel should be located, the model tunnel was placed on the sand bed at its designed position. Then the pluvial deposition of sand was continued. Similarly, the pile group (including the pile cap) was temporarily fixed at its design location (with the cap pinned to a temporary supporting beam) as the sand bed reached the toe level of the pile group. This was then followed by pluvial deposition of sand around the piles. When the sand hopper approached the pile cap during the subsequent sand raining, a guiding plate (inclined with an angle of $30^{\circ}$ relative to the vertical plane) was mounted under the opening of the sand hopper to guide the sand to fall into the gap within piles. Under this circumstance, the falling height of sand was changed to $300 \mathrm{~mm}$ to result in a relative density of about $65 \%$. By using the pluvial deposition method to form sand bed around the pile at $1 \mathrm{~g}$, the initial stress around the model pile is small. Subsequently, as the g-level increased during a test, the initial stress around the pile also increased under the $\mathrm{K}_{\mathrm{o}}$ conditions, which could be regarded as similar to that adjacent to a nondisplacement pile.

In each test, the $750 \mathrm{~mm}$ thick sand bed was formed layer by layer (i.e., $50 \mathrm{~mm}$ thick for each layer). After the preparation of each layer, the average density of the layer was deduced by measuring the weight and volume of sand used. Figure 4 shows the measured distributions of sand density with depth in all four centrifuge tests at $1 \mathrm{~g}$. It can be seen that the maximum difference in density is less than $0.6 \%$. Take Test ST for an example, the minimum density at the location of tunnel S is $1527 \mathrm{~kg} / \mathrm{m}^{3}$, which is $0.5 \%$ smaller than the maximum density of $1534 \mathrm{~kg} / \mathrm{m} 3$ obtained at about $725 \mathrm{~mm}$ below the surface of the sand bed. The measured average relative density (i.e., $D_{r}$ ) in each test is summarized in Table II. It can be seen that the percentage difference of $D_{r}$ between each tests is less than $2 \%$. This suggests that the soil samples prepared in these four tests are likely to be comparable.

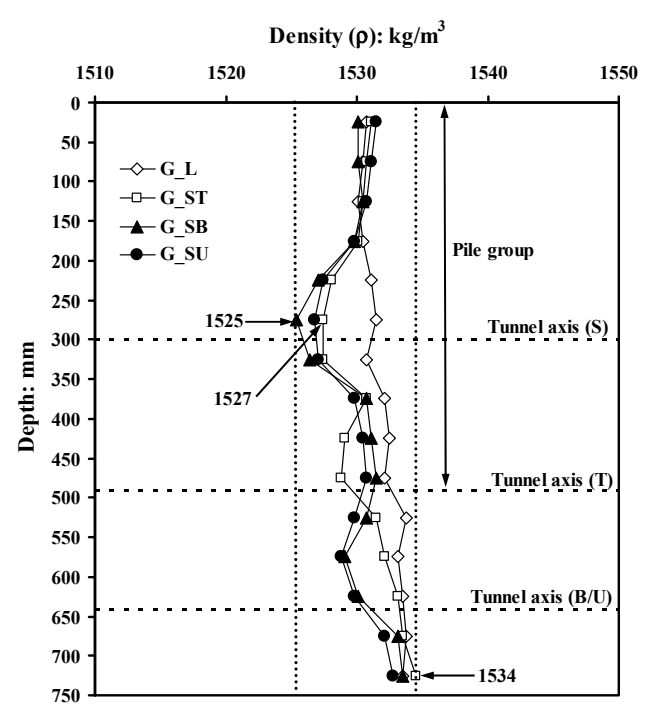

Fig. 4. Distributions of initial density of sand bed with depth in all four tests 


\section{E. Test Procedure}

After assembling the centrifuge model package, a dead weight was fixed on top of the pile cap to serve as working load (determined from the pile load test G_L). Then the whole package was mounted onto the swinging platform and spun up to $40 \mathrm{~g}$. Upon reaching $40 \mathrm{~g}$, in-flight twin tunnel excavations were simulated one after the other. Each tunnel was simulated in five stages, by draining away water from five rubber bags (with a 1.0\% volume loss for each), respectively. During the entire testing process, transverse tilting of the pile group, settlement of the pile group (in the center of the pile cap), axial load and bending movement along each pile were recorded. In the pile load test (Test G_L), no dead weight was placed on top of the pile cap at $1 \mathrm{~g}$. Instead, a hydraulic actuator was mounted onto the model box. After reaching $40 \mathrm{~g}$, in-flight pile load test was carried out by loading the pile cap incrementally with the hydraulic jack. Axial load acting on the pile cap and pile group settlement were measured during the pile load test.

\section{INTERPRETATION OF TESTS RESULTS}

All tests results are presented in this paper are in prototype scale, unless stated otherwise.

\section{A. Determination of Axial Load Bearing Capacity of the pile Group}

The principal objective of this study is to investigate the behaviour of existing $2 \times 2$ pile group (under working load) during advancement of twin (piggyback) tunneling. Therefore, it was mandatory to determine working load to be applied on pile group before commencement of tunnels. To achieve this objective an in-flight pile group load test (i.e. Test G_L) was carried out with absence of tunnels. The load was applied with an increment of $640 \mathrm{kN}$ (i.e. $400 \mathrm{~N}$ in model scale) to 12160 $\mathrm{kN}$ (i.e. $7600 \mathrm{~N}$ in model scale). Figure 5 shows load settlement relationship obtained from test G_L. The settlement is normalized by the pile diameter $\left(d_{p}\right)$. Based on the load settlement curve, ultimate capacity of the pile was deduced by a settlement acceptance failure criterion proposed by authors in [29] for single pile. The failure criterion is given by following expression:

$$
\delta_{p h, \text { max }} \cong 0.045 d_{p}+\frac{1}{2} \frac{P_{h} L_{p}}{A_{p} E_{p}}
$$

Where $\delta_{\text {ph,max }}$ is the maximum pile head movement which defines the ultimate load, $P_{h}$ is the pile head load, $L_{p}$ is the pile length, $E_{p}$ is the pile shaft elastic modulus, $A_{p}$ is the crosssectional area of the pile, and $d_{p}$ is the pile diameter. The reason for adopting [29]'s failure criterion is because it takes the effects of pile length into consideration. It can be seen from the Figure that the ultimate load (i.e., $8.3 \mathrm{kN}$ ) deduced from the failure criterion is sufficiently large to reveal a "yield" point (see "estimated yield point" in the Figure) of the loaddisplacement curve for the pile group. The "yield" point is estimated as a point from which the load-displacement curve starts to deviate from the tangent line passing through the origin. With a factor of safety (FOS) of 1.5, the working load was determined as $5.55 \mathrm{MN}$. A dead weight of $8.6 \mathrm{~kg}$ (equivalent to $5.55 \mathrm{MN}$ at prototype scale) was mounted on pile cap at 1g-level to serve as a working load on the pile group. Settlement of $3.0 \% \mathrm{~d}_{\mathrm{p}}$ (i.e. $24 \mathrm{~mm}$ ) of the pile group due to application working load can be predicted from load settlement curve (shown in Figure 5)

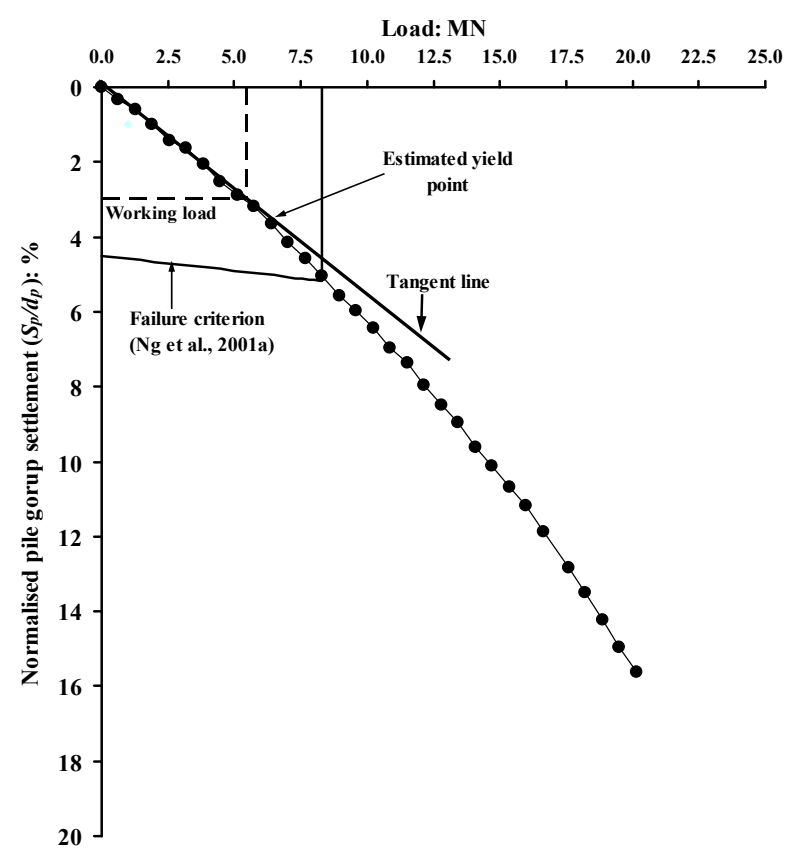

Fig. 5. Load settlement curve obtained from in-flight pile group load test (i.e. Test G_L)

\section{B. Settlement of Pile Group}

Figures $6 \mathrm{a}$ and $6 \mathrm{~b}$ show incremental settlement $\left(\mathrm{S}_{\mathrm{p}}\right)$ of pile group during advancement of the first tunnel (i.e., tunnel $\mathrm{S}$ ) and the second tunnel (i.e., tunnels T, B and $\mathrm{U}$ ) in all the three tests (i.e. G_ST, G_SB and G_SU). Construction stages of the tunnels are indicated by distance (i.e., y) between tunnel face to centerline of pile group (defined as monitoring section in Figure 6 ). The $S_{p}$ and $y$ are normalized by pile diameter $\left(d_{p}\right)$ and tunnel diameter (D), respectively. Measured incremental settlement of a single pile due to twin tunneling in a centrifuge [18], is also included in the figure for comparison. Centrifuge model package (including dimension of each component and volume loss due to tunneling) of the test reported by [18] are the same as that of Test G_ST in this study, except adopting single pile in their test. In addition, relative density of sand model in their test (i.e., 62\%) is slightly lower than that in this study (i.e., 65\%). Figure 6a shows that in all the three tests, $\mathrm{S}_{\mathrm{p}}$ of pile group due to advancement of the first tunnel (S) is very similar. This suggests repeatability of the three tests. Furthermore, it can be seen that $S_{p}$ of pile group increased almost linearly with tunneling stages (i.e., y/D). A similar trend can be observed from the reported centrifuge test of single pile subjected to tunneling near its pile shaft [18] In terms of magnitude, tunneling induced settlement of the single pile is much larger (about $300 \%$ larger) than that of the pile group, as expected. 


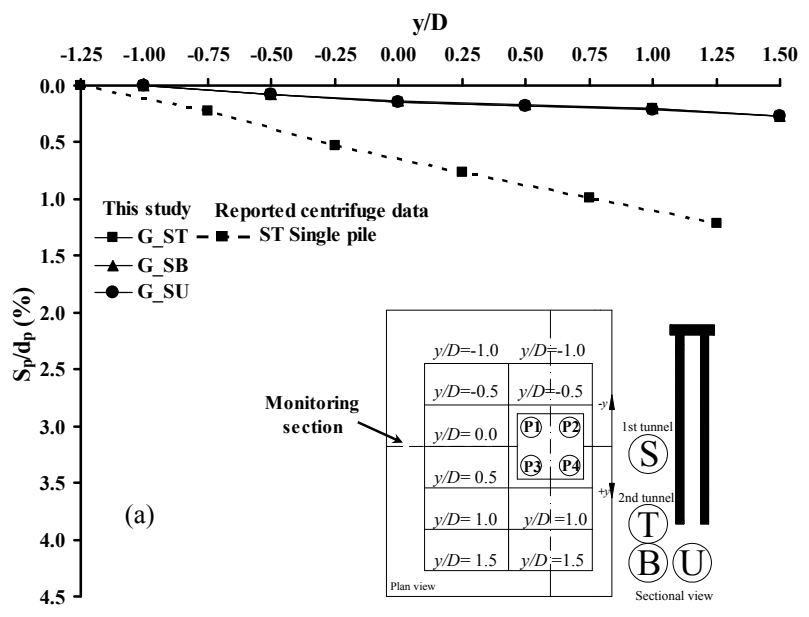

y/D

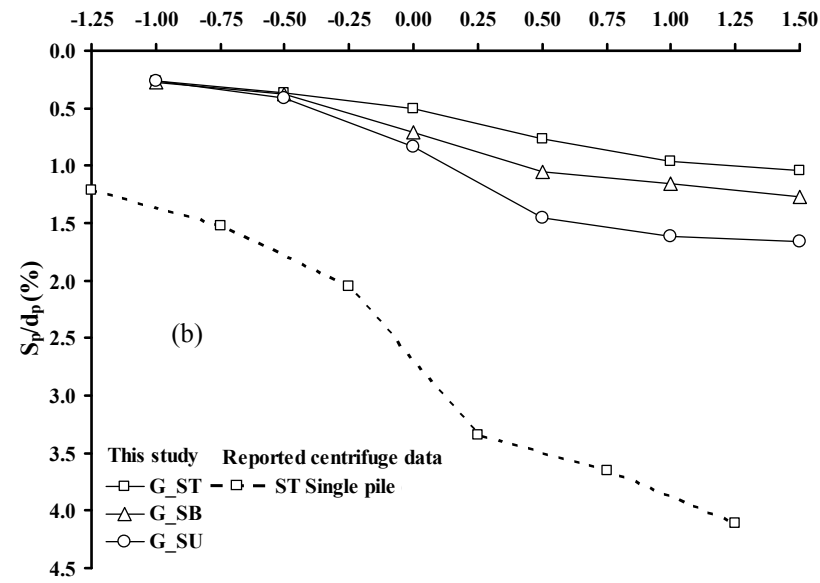

Fig. 6. Induced settlement of pile group due to advancement of: (a) 1st tunnel (i.e., tunnel S); (b) 2nd tunnel (i.e., tunnel T, B and U)

Different from tunneling near the mid-depth of the pile shaft, the subsequent tunneling adjacent to the pile toe (i.e., tunnels $\mathrm{S}, \mathrm{T}$ and $\mathrm{U}$ ) resulted in a non-linear increase of $\mathrm{S}_{\mathrm{p}}$ with construction stages (see Figure 6b). In all the three tests, settlement rate of $S_{p}$ of pile group increased as tunnel face approached the monitoring section (MS) and decreased as it moved away from MS. This trend is similar to that observed from a single pile subjected to tunneling near the pile toe [18]. While second tunnels (i.e., tunnels $\mathrm{T}, \mathrm{B}$ and $\mathrm{U}$ ) were constructed adjacent to the pile toe, the smallest $S_{p}$ was induced in test where tunnel is closest to the pile toe. The largest $S_{p}$ is caused by tunneling right underneath the pile (i.e., tunnel $U$ ). This is because tunneling right underneath the pile group resulted in the largest reduction of toe resistance of all four piles (discussed later). The reduction of toe resistance is compensated by mobilizing shaft resistance of all four piles, causing larger $S_{p}$ of pile group than that in the other two tests. These test results suggest that $S_{p}$ of pile group does not depend only on offset of tunnel from the pile toe, but also location of tunnel relative to the pile toe. Author in [30] carried out field measurement of axially loaded single piles subjected to tunneling either right underneath the pile, or underneath but with an offset of the pile. The measurements also show the largest $S_{p}$ of pile was caused by the tunneling right underneath the pile. The measured results shown in Figures $6 \mathrm{a}$ and $6 \mathrm{~b}$ imply that the tunnel driving distance simulated (2.5 times of tunnel diameter) is still insufficient to establish maximum pile settlement, although this should not affect the comparative nature and findings of this study significantly. By comparing Figures $6 \mathrm{a}$ and $6 \mathrm{~b}$, it can be seen that tunneling adjacent to the pile toe (in all three tests) caused much larger settlement than that near pile shaft. Total settlements of pile group (due to working load and twin tunneling) in Tests G ST, G SB and G SU are 32, 34 and $37 \mathrm{~mm}$ (i.e., 4.0, 4.3 and $4.6 \%$ of pile diameter), respectively. These three values satisfy a reliabilitybased serviceability criteria (i.e., $56 \mathrm{~mm}$ ), which was developed based on 95 buildings experiencing settlement [31].

\section{Tilting of Pile Cap}

Figure 7a compares transverse tilting of the pile cap due to the first tunneling in all the three tests. Each tilting was deduced as a ratio of differential settlement at two edges of the pile cap (measured by L1 and L3, see Figure 2 b) to the distance between them. Positive value means the pile cap tilts towards the first tunnel, and vice versa. In all the three tests, tilting of pile group due to the first tunneling (i.e., tunnel S) is very similar. Repeatability of the three tests is further confirmed. During the tunneling process, tilting of pile group increased almost linearly with excavation stages (i.e., y/D). After the first tunneling, incremental tilting in all three tests was about $0.05 \%$. During the second tunneling (see Figure 7b), pile cap tilts nonlinearly with excavation stages in Tests G_T and G_B. In both tests, increasing ratio of titling increased as tunnel face approached the monitoring section then decreased as it passed by. Larger tilting was always resulted in Test G_T than that in Test G B, as the former induced larger difference between stress release near front (P1) and rear pile (P2) (discussed later). While tunnel was excavated right underneath the pile toe (i.e., tunnel U), little tilting was induced. This is because front pile row (P1 and $\mathrm{P} 3)$ and rear pile row (P2 and $\mathrm{P} 4)$ are subjected to same amount of stress release in the test. Centrifuge test results reported by [18] show that that a single pile affected by the construction of a shallow tunnel and then followed by a deep tunnel would settle more than a pile response to a reversed tunneling sequence. Based on their test results, it may be deduced that a shallow tunnel constructed near a pile group and then followed by a deep tunnel would result in larger settlement of the front pile (closet to the tunnel being excavated) and hence larger differential settlement (i.e., tilting) between the front pile and the rear pile (furthest from the tunnel being excavated). After twin tunneling, the maximum tilting of pile group (occurred in Test G_ST) was about $0.2 \%$. This is exactly equal to allowable tilt limit (i.e. $0.2 \%$ ) suggested by Eurocode 7 [32] for building. It seems the "building" would be safe while subjected to construction of twin tunnels with configurations defined in this study (Figure $1)$. 

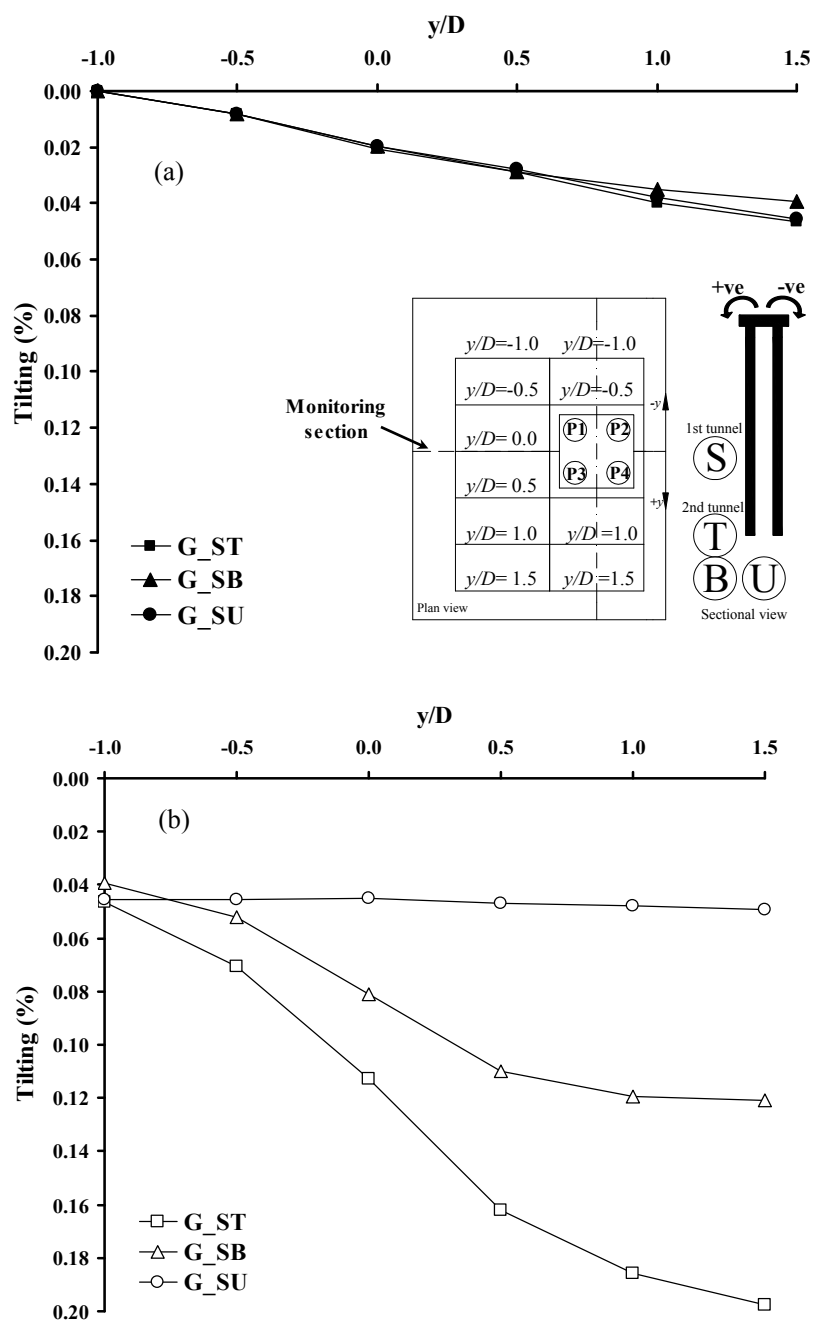

(b)

Fig. 7. Induced transverse tilting of the pile cap tilting due to advancement of: (a) 1st tunnel (i.e., tunnel S); (b) 2nd tunnel (i.e., tunnel T, B and U)

\section{Bending Moment Profile}

The tilting at the pile cap caused by twin tunneling (Figure 7) should have induced bending moment in piles. Figures $8 \mathrm{a}$, $8 \mathrm{~b}$ and $8 \mathrm{c}$ compare the measured incremental bending moment along the front pile (P1) and rear pile (P2) due to the twin tunneling in the three tests. A positive bending moments means that tensile stress was induced along pile shaft facing the first tunnel. Due to the first tunneling, the induced bending moment in each test is very similar. Therefore, bending moment caused by the first tunneling is only illustrated in Figure 9a. It can be seen that the maximum positive bending moment was induced near the location of the first tunnel, which caused stress release and hence soil displacement towards it. This positive bending moment was counter-balanced by negative bending moment near the pile cap. Due to the second tunneling, bending moment in Tests G_ST and G_SB increased significantly while it remains almost the same in Test G SU. These observations are consistent with measured tilting, shown in Figure 8. The most significant bending moment (i.e., $1120 \mathrm{kNm}$ ) was developed in both front and rear piles near pile cap in Test G_T. Based on [4], yield moment of the pile used in this study is about $800 \mathrm{kNm}$, which is less than the maximum bending moment developed in Test G_T. Authors in [4] carried out a series of centrifuge tests to investigate pile group responses due to tunneling in stiff clay. They also reported measured maximum induced bending moment at the head of front and rear piles when tunnel was constructed near and below the pile toes. However, the magnitudes of maximum bending moment are much smaller than bending moment capacity. Much larger bending moment measured in this study may be due to the reason that stiffness of medium dense sand (this study) is larger than that of stiff clay [4].

\section{E. Axial load distribution}

In this section, measured axial load of two typical piles in each row (front pile (P1) and rear pile (P2) (see insets in Figure 9) are selected for discussions. Figure 9a shows axial load distribution along the selected piles when the first and the second tunneling (i.e., tunnels $\mathrm{S}$ and $\mathrm{T}$ ) reaches the monitoring section (i.e. $y / D=0.0$ ) in test $G_{-} S T$. Before tunnel excavations (at working load condition), axial load distributions along both piles are similar. Therefore, only load distribution along the pile $\mathrm{P} 1$ is included for reference. It can be seen that about 45 and $46 \%$ of load carried by pile P1 (i.e. $1367 \mathrm{kN}$ ) at working load is carried by toe and lower half of shaft (i.e., $\left.0.5 \leq \mathrm{z} / \mathrm{L}_{\mathrm{p}} \leq 1.0\right)$ of the pile, respectively. When the first tunnel (i.e., tunnel $\mathrm{S}$ ) was constructed at $\mathrm{C} / \mathrm{D}=1.5$, the pile $\mathrm{P} 1$ experienced stress release which caused reduction of shaft resistances above the spring line of tunnel (S). Consequently, axial load acting on the pile group not only transferred to the lower half of front pile P1 shaft but also to its adjacent rear pile P2 to maintain equilibrium. Toe and shaft resistance at lower half of shaft of pile P1 increased by 8 and $10 \%$, respectively. This load transfer is similar to that observed from a single pile subjected to tunneling near the pile shaft [18]. However, in pile group load also transfer to rear pile as all pile are rigidly connected with pile cap. As second tunnel (i.e., tunnel T) was constructed near pile toe, stress release occurred near lower portion of shaft and toe of pile P1. Consequently, shaft resistance at lower shaft of pile P1 reduces by $66 \%$ and toe resistance was increased by $24 \%$ to carry the load. If the tunneling sequence were reversed (i.e., constructing the deep tunnel prior to the shallow one), a smaller reduction in the end bearing resistance and shaft resistance at the lower part of the pile is expected as revealed by authors in [18] from their investigation of the effects of tunneling sequence. Some of the load transferred to pile P2 and increased its head load by $24 \%$. To carry the load transferred from front pile P1, pile P2 mobilized its shaft capacity and toe resistance. The shaft and toe resistance increases by 30 and $35 \%$, respectively. The significant load re-distribution (24\%) between piles P1 and P2 in Test G_ST is likely to be associated with the differential settlement between the two piles (i.e., transverse tilting), which is the maximum among the three tests. If the tunneling sequences were reversed, smaller titling of the pile cap is expected (as discussed in the section "tilting of pile cap"), resulting smaller load re-distribution among piles. 
Figure $9 \mathrm{~b}$ shows the axial load distribution after the $1 \mathrm{st}$ tunneling and when the 2nd tunnel face reached the monitoring section in test G_SB. When the second tunnel (i.e., tunnel B) was constructed below pile toe $(C / D=3.7)$ and at an offset from pile group, front pile (P1) experiences largest stress release than the rear pile toe $(\mathrm{P} 2)$. As a result, the toe resistance of pile P1 decreases by $32 \%$. The pile has to settle to mobilize its shaft capacity to carry the load. Consequently, $20 \%$ of the load has been transferred to rear pile P2 to maintain equilibrium. Figure 9c shows the axial load distribution after the 1st tunneling and when the 2nd tunnel face reached the monitoring section in test G SB shows the axial load distribution along the pile P1 and pile P2 in test G SU. Since the second tunnel (i.e., tunnel U) is located right underneath of the pile group, the stress release due to tunnel $U$ causes reduction in toe resistance of both the piles. The toe resistance of both the piles was reduced by $48 \%$. To maintain equilibrium, pile group has to settle to mobilize more shaft resistance as a block. The most significant increase (58\%) took place at a depth ranging from 0.2 to 0.87 time of $\mathrm{L}_{\mathrm{p}}$. Consequently, pile group settlement in test G_SU is the largest of all the three tests. However, no tilting of pile cap induced during construction of second tunnel (U).Based on the horizontal stress acting on this portion of the pile shaft and frictional coefficient of the Toyoura sand-epoxy interface (i.e., 0.3 ), this incremental mobilized shaft resistance due to tunneling $U$ is equivalent to $13 \%$ of its ultimate value. Among all the three tests, the maximum mobilized shaft resistance (equal to $70 \%$ of the ultimate value) took place along the upper part of the piles $(0.2<\mathrm{Z} / \mathrm{L} p<0.87)$ in Test G_SU. In this test, the application of working load resulted in a mobilization of $57 \%$ while the remaining $13 \%$ was caused by twin tunneling SU.

\section{SUMMARY AND CONCLUSIONS}

A series of centrifuge model tests were carried out to investigate the effects of twin tunnel advancement on an existing pile group under working load in dry sand. In each centrifuge model test, twin tunneling was simulated threedimensionally one after the other in-flight. The conclusions drawn are based on four centrifuge tests in dry sand only. Any extrapolation from these results should be treated with caution. Based on the test results, the following conclusions may be drawn:

- When the first tunnel was excavated near mid depth of pile group shaft in each test, axial load acting on the pile group not only transferred to the lower half of front pile (nearest to tunnel) but also to the rear pile (furthest to tunnel). Load transfers between piles can increase the axial load of the rear pile by up to $24 \%$.

- Compared to the 1 st tunneling near pile shaft (i.e., tunnel S), the construction of the 2 nd tunnel adjacent to pile toe (i.e., tunnels T, B and $\mathrm{U}$ ) induces much larger settlement of the pile group. Among the three different scenarios (or tunnels T, $\mathrm{B}$ and $\mathrm{U}$ ), tunneling right underneath the pile due to tunnel $\mathrm{U}$ induced the largest pile settlement $(4.6 \%$ of pile diameter) and incremental mobilization of shaft resistance (13\%). This is because stress release right underneath the pile group resulted in the largest reduction of toe resistance of the pile group. The reduction of toe resistance is compensated mainly by mobilizing shaft resistance of all four piles. In spite of the relatively large settlement, little tilting of pile cap was induced by the 2nd tunnel underneath the pile group, as stress release below each pile toe was symmetrical.

- Measured total settlements of pile group (due to working pile load and effects of twin tunneling) in Tests G_ST, G_SB and G_SU are 32,34 and $37 \mathrm{~mm}$, respectively. Based on pile acceptance criterion, these induced extra settlements due to twin tunneling correspond to an apparent loss of pile group capacity of 18,23 and $30 \%$, respectively.

- Compared to the construction of the 2 nd tunnels B and $U$, the advancement of the 2 nd tunnel, $T$, near the toe of the pile group caused a larger difference of stress release in soil around the front pile and the rear pile, leading to the largest $0.2 \%$ transverse tilting of pile cap. Correspondingly, a significant bending moment (being 1.4 times of its ultimate bending capacity) was developed near the pile head. This implies that 2nd tunnel construction using a volume loss (1\%) near the toe of a pile group may potentially cause structural failure of piles, even though the induced tilting does not exceed the allowable limit suggested by [32].

\section{REFERENCES}

[1] C. H. Pang, K. Y. Yong, Y. K. Chow, "Three dimensional numerical simulation of tunnel advancement on adjacent pile foundation" Underground Space Use: Analysis of the Past and Lessons for the Future, pp. 1141-1147. London: Taylor and Francis, 2005

[2] A. Bezuijen, J. S. van der Schrier, "The influence of a bored tunnel on pile foundations”, Centrifuge'94, Rotterdam, Netherlands. pp. 681-686, 1994

[3] L. T. Chen, H. G. Poulos, N. Loganathan, "Pile responses caused by tunneling", Journal of Geotechnical and Geoenvironmental Engineering, Vol. 125, No. 3, pp. 207-215, 1999

[4] N. Loganathan, H .G. Poulos, D. P. Stewart, "Centrifuge model testing of tunneling-induced ground and pile deformations", Geotechnique, Vol. 50, No.3, pp. 283-294, 2000

[5] H. Mroueh, I. Shahrour, "Three-dimensional finite element analysis of the interaction between tunneling and pile foundations", International Journal for Numerical and Analytical Methods in Geomechanics, Vol. 26, No. 3, pp. 217-230, 2002

[6] S. W. Jacobsz, J. R. Standing, R. J. Mair, T. Hahiwara, T. Suiyama, "Centrifuge modeling of tunneling near driven piles", Soil and Foundations, Vol. 44, No. 1, pp. 49-56, 2004

[7] C. Y. Cheng, G. R. Dasari, Y. K. Chow, C. F. Leung, "Finite element analysis of tunnel-soil-pile interaction using displacement controlled model", Tunneling and Underground Space Technology, Vol. 22, No. 4 , pp. 450-466, 2007

[8] Y. J. Lee, Tunneling Adjacent to a Row of Loaded Piles, PhD Thesis, University College London, University of London, 2004

[9] C. J. Lee, "Numerical analysis of the interface shear transfer mechanism of a single pile to tunneling in weathered residual soil" Computers and Geotechnics, Vol. 42, 193-203, 2012

[10] P. Kitiyodom, T. Matsumoto, K. Kawaguchi, "A simplified analysis method for piled raft foundations subjected to ground movements induced by tunneling", International Journal for Numerical and Analytical Methods in Geomechanics, Vol. 29, No. 15, pp. 1485-1507, 2005

[11] G. T. K. Lee, C. W. W. Ng, "The effects of advancing open face tunneling on an existing loaded pile", Journal of Geotechnical and Geoenvironmental Engineering, Vol. 131, No. 2, pp. 193-201, 2005 

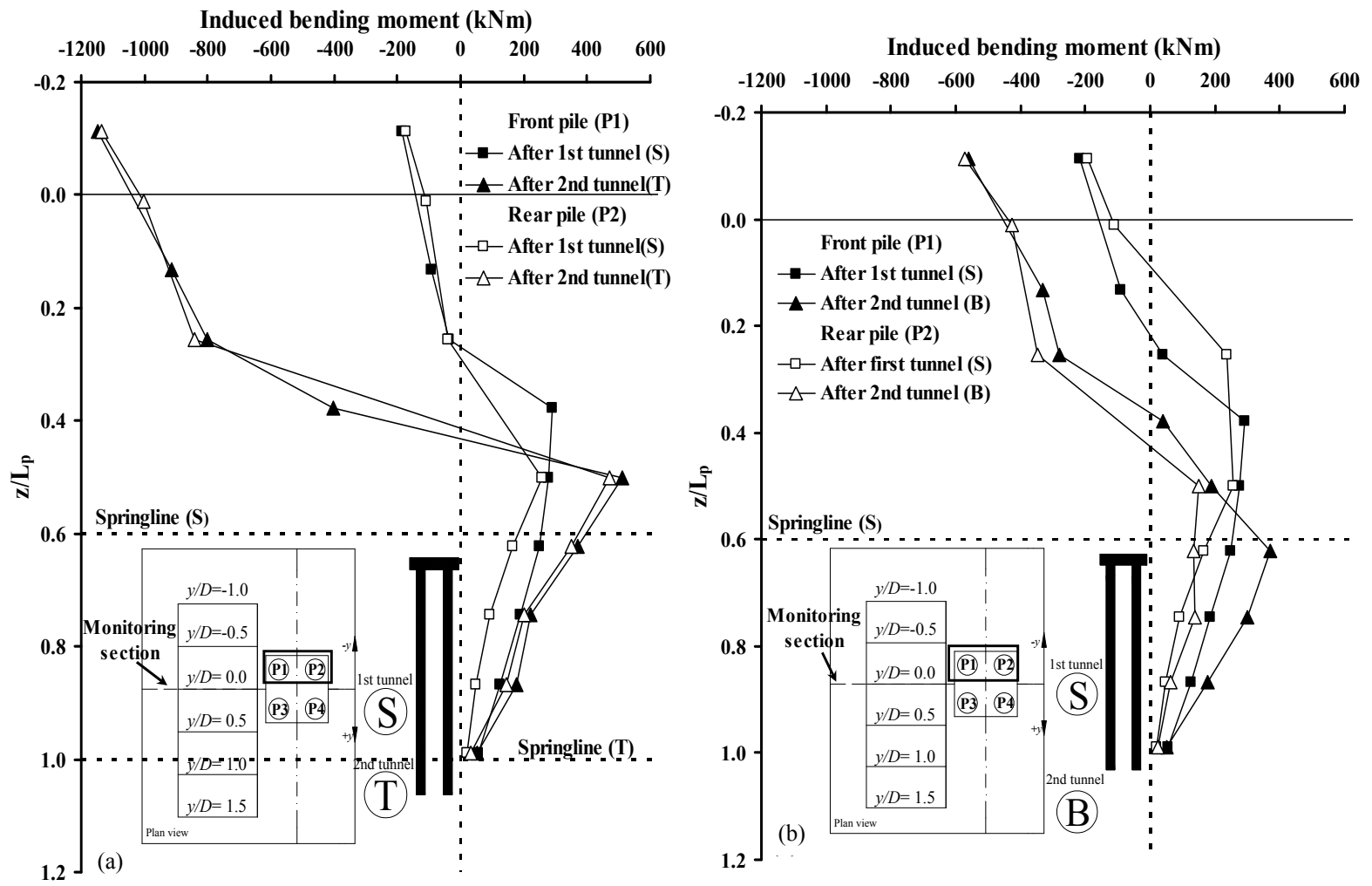

Induced bending moment $(\mathrm{kNm})$

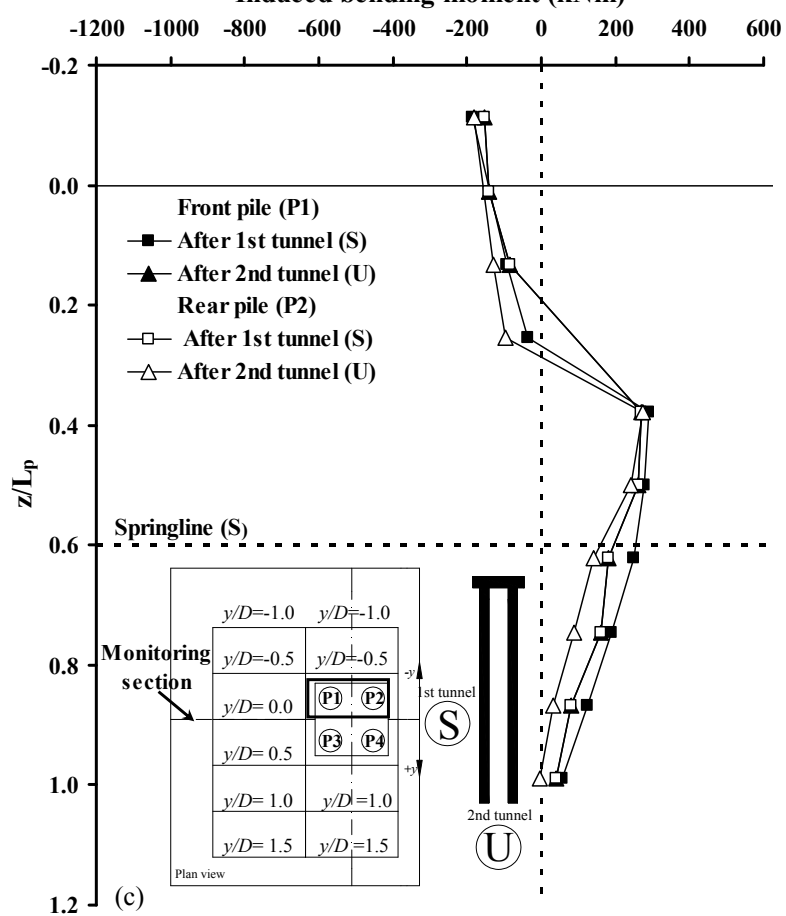

Fig. 8. Bending moment in front pile (P1) and rear pile (P2) due to advancement of both tunnels in: (a) Test G_ST (b) Test G_SB (c) Test G_S 

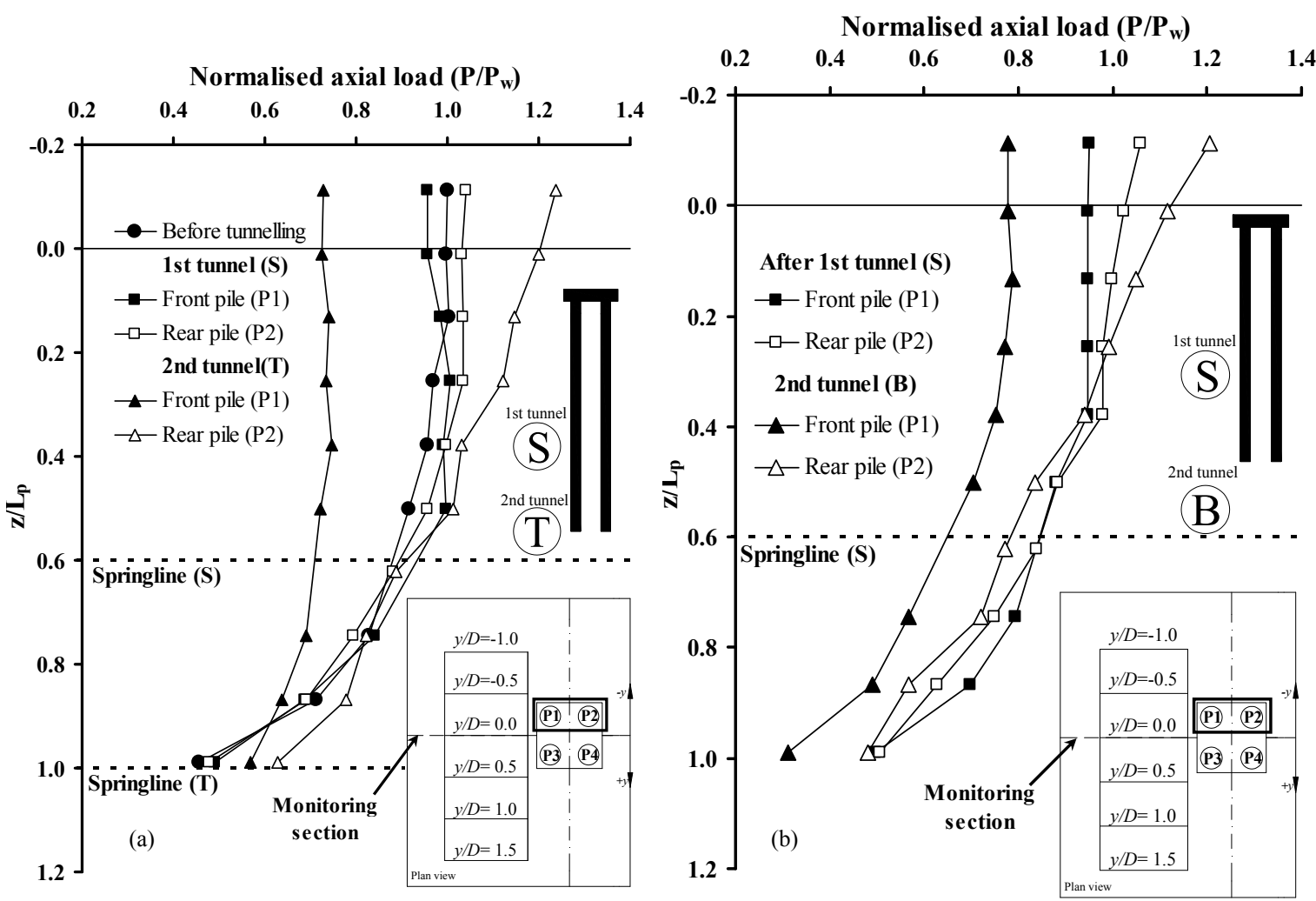

Normalised axial load $\left(\mathbf{P} / \mathbf{P}_{\mathrm{w}}\right)$

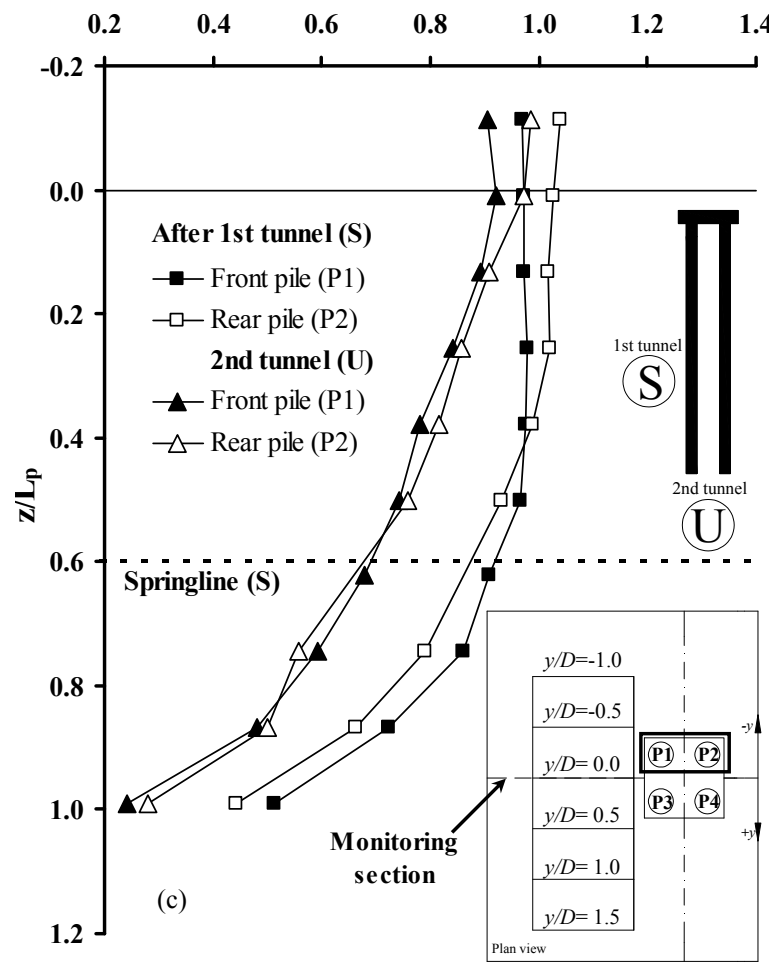

Fig. 9. Axial force distribution in front pile (P1) and rear pile (P2) due to advancement of: (a) twin tunnels in Test G_ST (i.e., tunnels S and T); (b) 2nd tunnel in Test G_SB (i.e., tunnel B); (c) 2nd tunnel in Test G_SU (i.e., tunnel U) 
[12] C. J. Lee, S. W. Jacobsz, "The influence of tunneling on adjacent piled foundations", Tunneling and Underground Space Technology, Vol. 21, No. 3-4, pp. 430, 2006

[13] C. J. Lee, K. H. Chiang, "Responses of single piles to tunneling-induced soil movements in sandy ground", Canadian Geotechnical Journal, Vol. 44, No.10, pp. 1224-1241, 2007

[14] M. Huang, C. Zhang, Z. Li, "A simplified analysis method for the influence of tunneling on grouped piles", Tunneling and Underground Space Technology, Vol. 24, No. 4, pp. 410-422, 2009

[15] S. W. Lee, C. K. M. Choy, W. W. L. Cheang, W. Swolfs, R. Brinkgreve, "Modeling of tunneling beneath a building supported by friction bored piles", 7th Southeast Asian Geotechnical Conference, pp. 215-218, 2010

[16] M. Devriendt, M. Williamson, "Validation of methods for assessing tunneling-induced settlements on piles", Ground Engineering, pp.25-30, 2011

[17] C. W. W. Ng, H. Lu, S. Y. Peng, "Three-dimensional centrifuge modeling of effects of twin tunneling on as existing pile", Tunneling and Underground Space Technology, Vol. 35, pp. 189-199, 2013

[18] C. W. W. Ng, H. Lu, "Effects of construction sequence of twin tunneling at different depth on a single pile", Canadian Geotechnical Journal, Vol. 51, pp. 173-183, 2013

[19] C. W. W. Ng, P. A. Van Laak, W. H. Tang, X. S. Li, L. M. Zhang, "The Hong Kong geotechnical centrifuge", 3rd International Conference on Soft Soil Engineering, Hong Kong, pp. 225-230, 2001

[20] C. W. W. Ng, P. A. Van Laak, L. M. Zhang, W. H. Tang, G. H. Zong, Z. L. Wang, G. M. Xu, S. H. Liu, "Development of a four-axis robotic manipulator for centrifuge modeling at HKUST", International Conference on Physical Modeling in Geotechnics, St. John's Newfoundland, Canada, pp. 71-76, 2002

[21] R. Rowe, G. Kack, "A theoretical examination of the settlements induced by tunneling: four case histories", Canadian Geotechnical Journal, Vol. 20, No. 2, pp. 299-314, 1983
[22] A. M. Marshall, Tunneling in sand and its effect on pipelines and piles. PhD Thesis, Cambridge University, 2009

[23] R. J. Mair, R. N. Taylor, A. Bracegirdle, "Subsurface settlement profiles above tunnels in clay", Geotechnique, Vol. 43, No. 3, pp. 315-320, 1993

[24] A. A. Balkema, "Bored tunneling in the urban environments", 14th International Conference on Soil Mechanics and Foundation Engineering, Hamburg, Germany, Vol. 4, pp. 2353-2385, 1997

[25] M. Uesugi, H. Kishida, "Tests of the interface between sand and steel in the simple shear apparatus", Geotechnique, Vol. 37, No. 1, pp. 45-52, 1987

[26] V. Fioravante, "On the shaft friction modeling of non-displacement piles in sand", Soils and Foundations, Vol. 42, No.2, pp. 23-33, 2002

[27] K. Ishihara, "Liquefaction and flow failure during earthquakes", Geotechnique, Vol. 43, No. 3, pp. 351-415, 1993

[28] L. D. Fuglsang, N. K. Ovesen, The theory of modeling to centrifuge studies, Centrifuge in soil mechanics, Craig, James and Schofield, Balkema, Rotterdam, 1988

[29] C. W. W. Ng, T. L. Y. Yau, J. H. M. Li, W. H. Tang, "New failure load criterion for large diameter bored piles in weathered geomaterials", Journal of Geotechnical and Geoenvironmental Engineering, Vol. 127, No. 6, pp. 488-498, 2001

[30] D. Selemetas, The response of full-scale piles and pile structures to tunneling, $\mathrm{PhD}$ Thesis, Cambridge University, 2005

[31] L. M. Zhang, A. M. Y. Ng, "Probabilistic limiting tolerable displacements for serviceability limit state design of foundations", Geotechnique, Vol. 55, No. 2, pp. 151-161, 2005

[32] CEN Eurocode 7 part 1, "Geotechnical design: General rules, Final Draft”, prEN 1997-1, Brussels: European Committeef or Standardization (CEN), 2001 